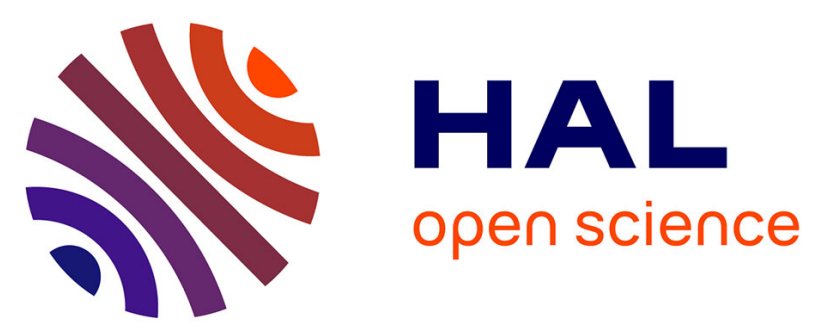

\title{
Hydrophobic VOC absorption in two-phase partitioning bioreactors; influence of silicone oil volume fraction on absorber diameter.
}

Eric Dumont, Guillaume Darracq, Annabelle Couvert, Catherine Courriol, Abdeltif Amrane, Diane Thomas, Yves Andres, Pierre Le Cloirec

\section{To cite this version:}

Eric Dumont, Guillaume Darracq, Annabelle Couvert, Catherine Courriol, Abdeltif Amrane, et al.. Hydrophobic VOC absorption in two-phase partitioning bioreactors; influence of silicone oil volume fraction on absorber diameter.. Chemical Engineering Science, 2012, 71, pp.146-152. 10.1016/j.ces.2011.12.017 . hal-00868983

\section{HAL Id: hal-00868983}

https://hal-univ-rennes1.archives-ouvertes.fr/hal-00868983

Submitted on 17 Jan 2014

HAL is a multi-disciplinary open access archive for the deposit and dissemination of scientific research documents, whether they are published or not. The documents may come from teaching and research institutions in France or abroad, or from public or private research centers.
L'archive ouverte pluridisciplinaire HAL, est destinée au dépôt et à la diffusion de documents scientifiques de niveau recherche, publiés ou non, émanant des établissements d'enseignement et de recherche français ou étrangers, des laboratoires publics ou privés. 
Hydrophobic VOC absorption in two-phase partitioning bioreactors; influence of silicone oil volume fraction on absorber diameter.

Eric Dumont $^{\mathrm{a}}$, Guillaume Darracq ${ }^{\mathrm{b}, \mathrm{c}}$, Annabelle Couvert ${ }^{\mathrm{b}, \mathrm{c}}$, Catherine Couriol ${ }^{\mathrm{b}, \mathrm{c}}$, Abdeltif Amrane $^{\mathrm{b}, \mathrm{c}}$, Diane Thomas ${ }^{\mathrm{d}}$, Yves Andrès ${ }^{\mathrm{a}}$, Pierre Le Cloirec ${ }^{\mathrm{b}, \mathrm{c}}$.

${ }^{\text {a }}$ UMR CNRS 6144 GEPEA, École des Mines de Nantes, La Chantrerie, 4 rue Alfred Kastler, B.P. 20722, 44307 Nantes Cedex 3, France.

${ }^{\mathrm{b}}$ École Nationale Supérieure de Chimie de Rennes, CNRS, UMR 6226, Av. du Général Leclerc, CS 50837, 35708 Rennes Cedex 7, France.

${ }^{c}$ Université européenne de Bretagne, 35000 Rennes, France.

${ }^{\mathrm{d}}$ Faculté Polytechnique de Mons, 56 rue de L'Epargne, B-7000 Mons, Belgium.

Corresponding author:

Eric Dumont (eric.dumont@mines-nantes.fr)

Tel: +33(0)2 51858266

Fax: +33 (0)2 51858299

École des Mines de Nantes, La Chantrerie, 4 rue Alfred Kastler, B.P. 20722, 44307

Nantes Cedex 3, France. 


\begin{abstract}
A methodology to determine the diameter of an absorber contacting a gas phase and two immiscible liquid phases (water/silicone oil mixture) is presented. The methodology is applied to a countercurrent gas/liquid randomly packed column for the absorption of three VOCs (toluene, dimethyl sulfide, or dimethyl disulfide). Whatever the silicone oil volume fraction, Eckert's generalized pressure drop correlation was used. The results present the change in the column diameter through the change in the dimensionless ratio $\mathrm{D}(\phi) / \mathrm{D}(\phi=1)$ versus the silicone oil volume fraction for the same operating conditions.

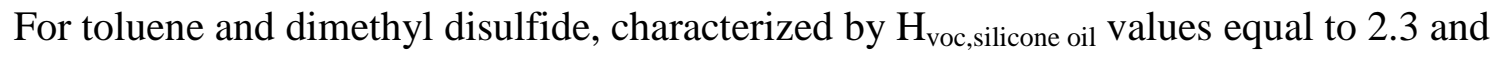
$3.4 \mathrm{~Pa} \cdot \mathrm{m}^{3} \cdot \mathrm{mol}^{-1}$ respectively, it is highlighted that it is unwise to use water/silicone oil mixtures for mass transfer. In these cases, the contact between the polluted air and pure silicone oil requires roughly the same amount of silicone oil as for a (90/10 v/v) water/silicone oil mixture, but enables a 2-fold decrease in the column diameter. For dimethyl sulfide, which is characterized by a larger partition coefficient value $\left(\mathrm{H}_{\mathrm{voc}, \text { silicone oil }}=17.7 \mathrm{~Pa} \cdot \mathrm{m}^{3} \cdot \mathrm{mol}^{-1}\right)$, the mass transfer operation should not be considered because large amounts of silicone oil are required (whatever the silicone oil volume fraction), which is not acceptable from an economic point of view.

The feasibility of using a bioscrubber for the treatment of hydrophobic pollutants depends mainly on the partition coefficient $\mathrm{H}_{\mathrm{voc}, \text { silicone oil }}$ VOC absorption in TPPB

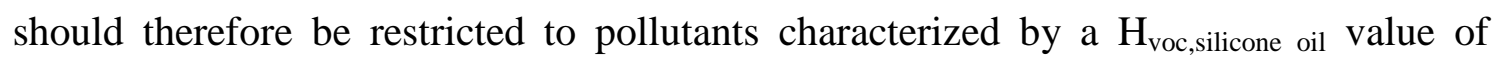
around 3 to $4 \mathrm{~Pa} \cdot \mathrm{m}^{3} \cdot \mathrm{mol}^{-1}$ or less. In this case, absorption can be efficiently carried out in a biphasic air/silicone oil system.
\end{abstract}

Key-words: Mass transfer; Absorption; Packed bed; Design; Partition coefficient; Multiphase reactor 


\section{Introduction}

The biological treatment of air loaded with Volatile Organic Compounds (VOC) requires the mass transfer of pollutants from the gas phase to an aqueous phase. However, VOC are often scarcely soluble in water and the addition of a non-aqueous liquid phase (NAPL), immiscible with water, is usually proposed in order to improve the mass transfer of pollutants (Kundu et al., 2003; Dumont et al., 2006a). In such cases, hydrophobic VOC treatment can be achieved in a bioscrubber in which the pollutant is first absorbed into a liquid phase, consisting of a mixture of an aqueous phase and a NAPL, before being introduced into a two-phase partitioning bioreactor (TPPB; Daugulis, 2001). The VOC is then gradually transferred from the organic phase to the aqueous phase in order to be degraded by micro-organisms present in the latter. Once regenerated, the mixture is recycled towards the absorber (Fig. 1).

Unfortunately, to date, hydrophobic VOC removal is still restricted to laboratory-scale experiments due to a lack of the knowledge required to scale up. One of the main difficulties is the calculation of the diameter (D) of the column allowing the VOC mass transfer between the gas phase and the water/NAPL mixture. According to the principles of absorption, the design of gas/liquid absorption systems is controlled since the contacting phases are well defined in terms of molar flow rates and physicochemical properties (McCabe et al., 1993). For a given gas flow rate, the calculation of the cross-section of the gas/liquid contactor involves the determination of the minimum liquid flow, which mainly depends on the solute partition coefficient between the gas and liquid phases. However, when the liquid phase consists of a mixture of an aqueous phase and a non-aqueous liquid phase, the physico-chemical properties of the mixture are not sufficiently known to enable the design to be carried out.

The aim of this study is to solve this issue by introducing a methodology to calculate the column diameter as a function of the volumetric fraction of the organic solvent in the mixture. The methodology is based, firstly, on the determination of the partition coefficient of the VOC between the gas and the mixture of immiscible liquids (Darracq et al., 2010), and secondly, on a new concept of mass transfer between phases called the "equivalent absorption capacity" (Dumont et al., 2010). The calculation procedure is applied to a countercurrent packed tower treating a given gas flow rate loaded with 
VOC (toluene, dimethyl sulfide (DMS) or dimethyl disulfide (DMDS)) by absorption in water/silicone oil mixtures of varying composition.

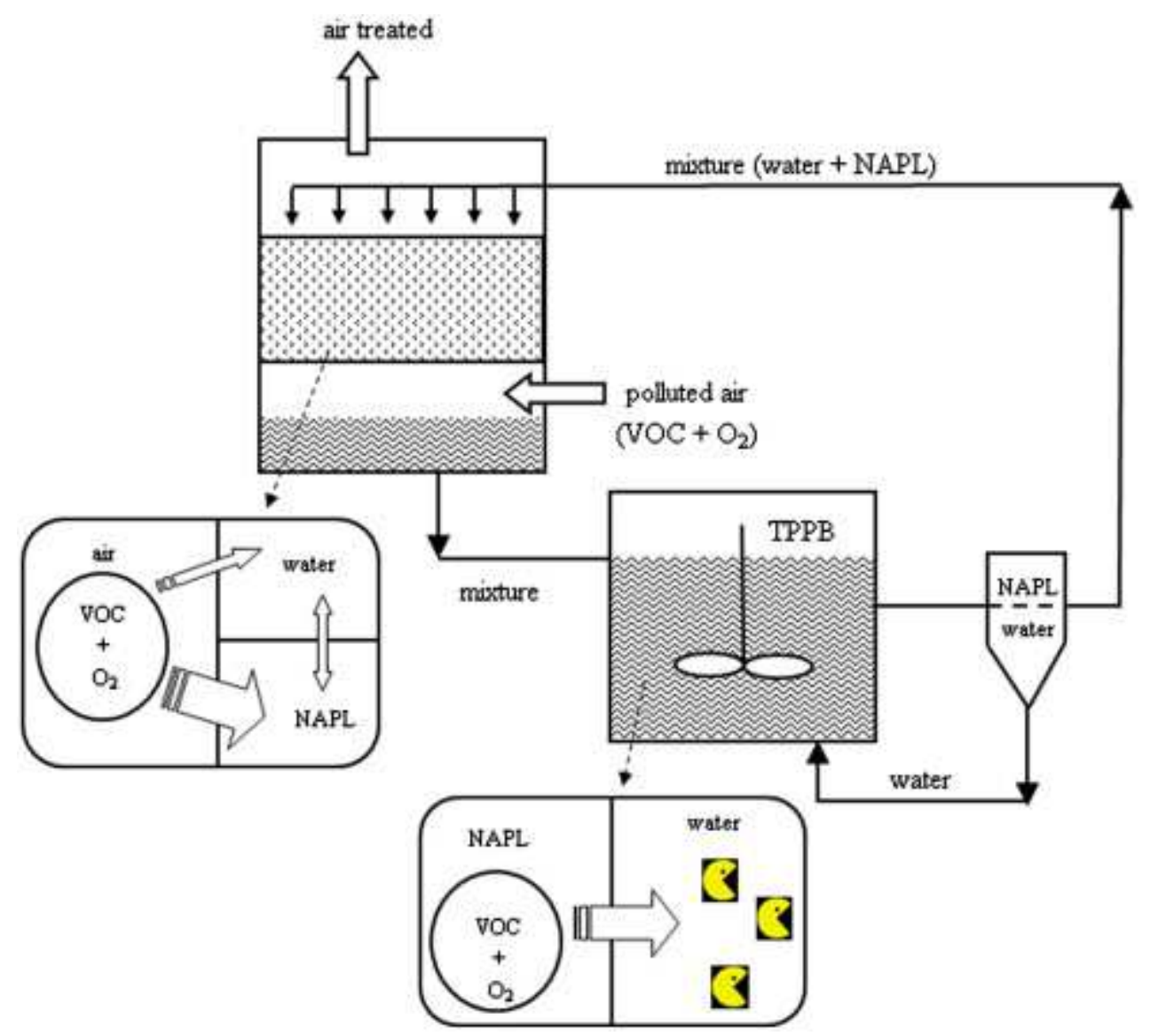

Fig. 1. Bioprocess for VOC treatment (NAPL=silicone oil).

\section{VOC partition coefficients in water/silicone oil mixtures}

According to the VOC to be transferred, the non-aqueous liquid phase must be selected in order to improve mass transfer and thus reduce the liquid flow rate needed for absorption. In this study, the calculation is based on the use of silicone oil as the NAPL whose ability to improve hydrophobic VOC mass transfer has been clearly demonstrated (Dumont et al., 2006b; Darracq et al., 2010). The physical properties of the silicone oil (dimethylpolysiloxane; Rhodorsil® fluids 47V5 from the Rhodia Company, France) are: viscosity: $\eta=5 \mathrm{mPa} . \mathrm{s}$; density: $\rho=930 \mathrm{~kg} / \mathrm{m}^{3}$; molecular weight: $\mathrm{M}=740 \mathrm{~g} / \mathrm{mol}$. According to the VOC to be treated, the composition of the mixture must be judiciously chosen in order to achieve an optimal mass transfer. On one 
hand, it can be reasonably assumed that an increase in the silicone oil volume fraction in the mixture will lead to a dramatic decrease in the mixture flow rate needed for absorption, and will thus reduce the vessel diameter and the capital costs of the process. In this case, it seems obvious to contact the gas phase with pure silicone oil in order to design a column diameter as small as possible. On the other hand, as silicone oil is a relatively expensive product, the amount to be used should be limited in order to reduce the operating cost. Consequently, one of the challenges of this study is to determine precisely the amount necessary for the VOC mass transfer in relation to the mixture composition (in order to select the optimal one).

The major problem for the design of such an absorber depends directly on the knowledge of the equilibrium solubility of the VOC between the gas phase and the water/silicone oil mixture. As demonstrated by Dumont et al. (2010) from experimental measurements, the VOC partition coefficient between air and a water/silicone oil mixture $\left(\mathrm{H}_{\mathrm{voc} \text {,mixture }}\right)$ can be expressed as a function of the VOC partition coefficients for air/water and air/silicone oil respectively, and as a function of the silicone volume fraction in the mixture $(\phi)$ :

$\frac{1}{H_{v o c, \text { mixture }}}=\frac{(1-\phi)}{H_{v o c, \text { water }}}+\frac{\phi}{H_{v o c, \text { silicone oil }}}$

Values of the air/water and air/silicone oil partition coefficients for the three studied VOC are summarized in Table $1 . \mathrm{m}_{\mathrm{R}}$ represents the ratio of partition coefficients. As

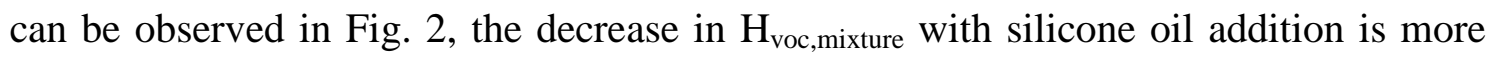
pronounced for increasing $\mathrm{m}_{\mathrm{R}}$ ratios. Moreover, it is possible to consider that the VOC absorption capacity of any water/silicone oil mixture (corresponding to the sum of both water and silicone oil absorption capacities) is equal to the VOC absorption capacity of

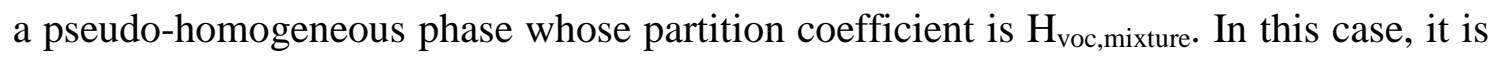
assumed that any water/silicone oil mixture can be characterized by specific physical properties (mainly molecular weight and density) similar to those of a single liquid phase. This empirical idea, developed by Dumont et al. (2010), has been called the "equivalent absorption capacity" concept. 


\section{DMDS DMS Toluene}
Partition coefficient in water $\left(H_{v o c \text {, water }}\right)$
$111.9 \quad 182.1680$
Partition coefficient in silicone oil ( $\left.H_{\text {voc,silicone oil }}\right) 3.4 \quad 17.7 \quad 2.3$
Ratio $m_{R}=H_{v o c, \text { water }} / H_{v o c, \text { silicone oil }}$
$33 \quad 10 \quad 296$

Table 1. VOC partition coefficients at $T=298 \mathrm{~K}\left(\mathrm{~Pa} \mathrm{~m}^{3} \mathrm{~mol}^{-1}\right.$; Dumont et al., 2010).

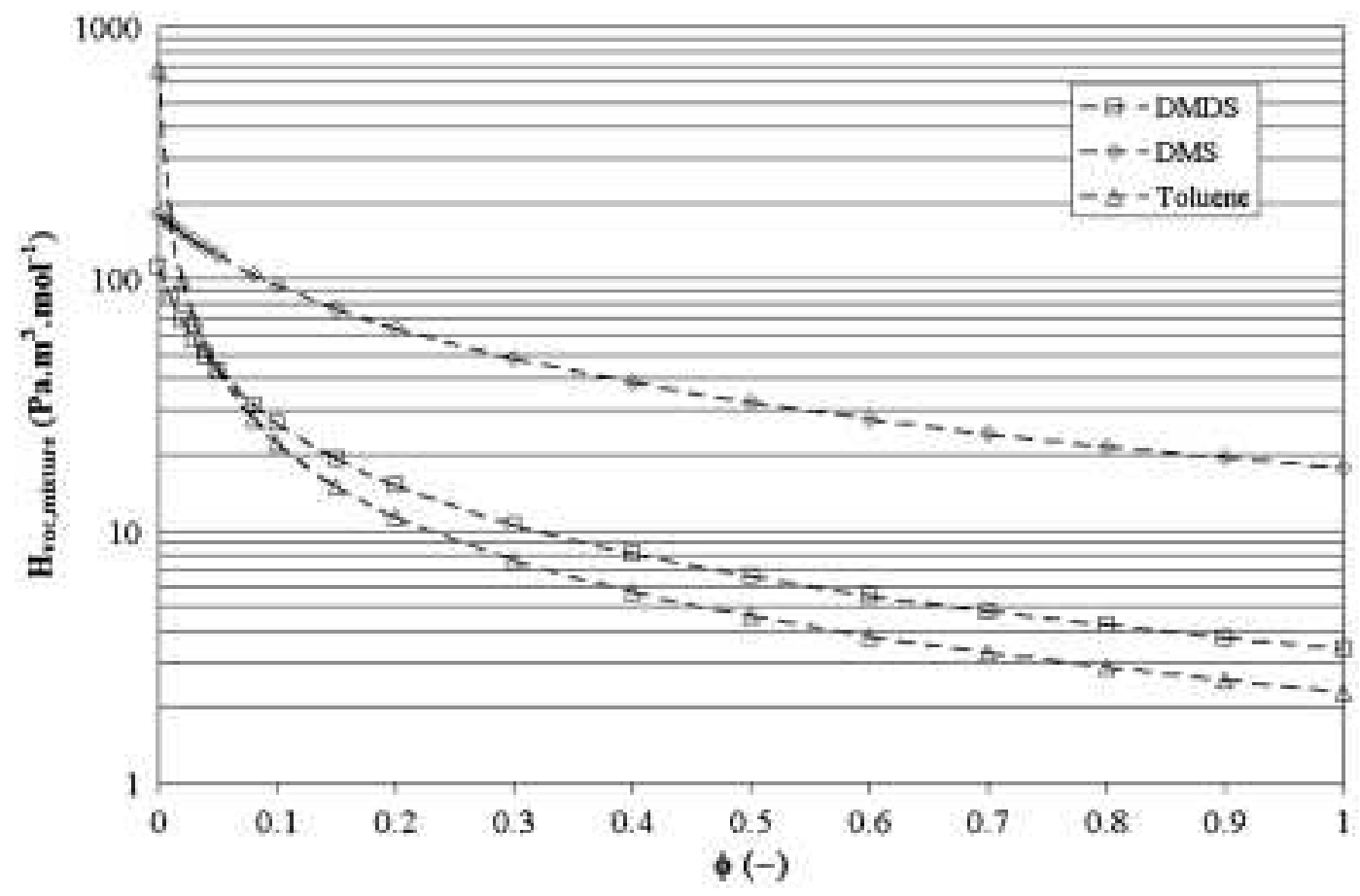

Fig. 2. VOC partition coefficients between air and water/silicone oil mixtures.

\section{3. "Equivalent absorption capacity" concept}

This empirical "equivalent absorption capacity" concept is based on experimental mass transfer measurements (DMDS, DMS and toluene) carried out in a batch reactor between air and various water/silicone oil mixtures. The experimental procedure has been previously described (Dumont et al., 2010) and it was finally demonstrated that the absorption capacity of any water/silicone oil mixture is equivalent to that of a pseudohomogeneous phase whose physical properties (molecular weight $\mathbf{M}_{\text {mixture }}$ and density $\left.\rho_{\text {mixture }}\right)$ can be expressed using Eqs. (2-3). 


$$
M_{\text {mixture }}=(1-\phi) M_{\text {water }} \frac{H_{v o c, \text { mixture }}}{H_{v o c, \text { water }}} \frac{\rho_{\text {mixture }}}{\rho_{\text {water }}}+\phi M_{\text {silicone oil }} \frac{H_{v o c, \text { mixture }}}{H_{\text {voc, silicone oil }}} \frac{\rho_{\text {mixture }}}{\rho_{\text {silicone oil }}}
$$

$$
\rho_{\text {mixture }}=(1-\phi) \rho_{\text {water }} \frac{H_{v o c, \text { mixture }}}{H_{v o c, \text { water }}}+\phi \rho_{\text {silicone oil }} \frac{H_{v o c, \text { mixture }}}{H_{\text {voc, silicone oil }}}
$$

As can be observed in Eqs. (2-3), the mathematical expressions of $\mathbf{M}_{\text {mixture }}$ and $\rho_{\text {mixture }}$ depend on the physical properties of water and silicone oil, logically balanced according to their proportions in the mixture (i.e. (1- $\phi) \mathrm{M}_{\text {water }}$ and $\phi \mathrm{M}_{\text {silicone oil }} ;(1-\phi) \rho_{\text {water }}$ and $\phi \rho_{\text {silicone oil }}$ respectively). However, the physical properties of water and silicone oil should also be balanced using the non-dimensional ratios $\mathrm{H}_{\mathrm{voc}, \text { mixture }} / \mathrm{H}_{\mathrm{voc} \text {,water }}$ and $\mathrm{H}_{\mathrm{voc}, \text { mixture }} / \mathrm{H}_{\mathrm{voc}}$,silicone oil, which must be explained. From experimental data, it has been established that material balances in both molar and volume units can only be satisfied if the actual absorption capacities of water and silicone oil, respectively, are considered. Let us take an example, such as DMDS absorption using a (90/10 v/v) water/silicone oil mixture $(\phi=0.1)$. If a given volume of this mixture is considered, the absorption is

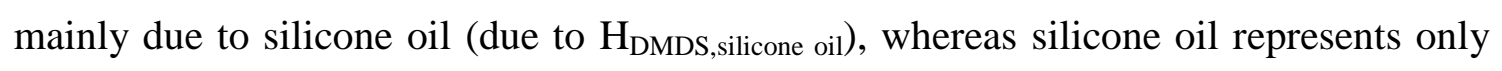
$0.3 \%$ of the total mole number present in the mixture (Fig. 3). On the contrary, water, which represents the major element in the mixture (from the mole number point of view), has a weak absorption capacity (due to $\mathrm{H}_{\mathrm{DMDS} \text {,water }}$ ). In order to satisfy the material balance expressed in molar units, it has been shown that the importance of the mole number of water must be moderated by using a correction factor $\left(\mathrm{H}_{\mathrm{voc}, \text { mixture }} / \mathrm{H}_{\mathrm{voc}, \text { water }}\right)$ so that the actual absorption capacity can be taken into account. In the same way, the importance of the mole number of silicone oil must be corrected by

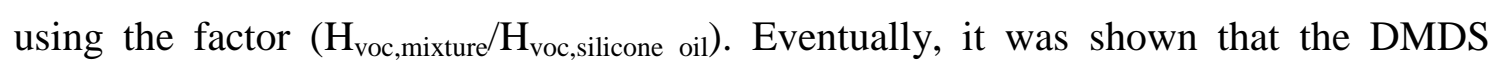
absorption capacity by a $(90 / 10 \mathrm{v} / \mathrm{v})$ water/silicone oil mixture is equivalent to the absorption capacity of a pseudo-homogeneous phase whose: (i) partition coefficient calculated using Eq. (1) is equal to $26.7 \mathrm{~Pa}^{3} \mathrm{~m}^{3} \cdot \mathrm{mol}^{-1}$ corresponding to a 4-fold decrease with regard to $\mathrm{H}_{\mathrm{DMDS}}$,water (Fig. 2); and (ii) molecular weight is equal to $594 \mathrm{~g} / \mathrm{mol}$ and whose density is $945 \mathrm{~kg} / \mathrm{m}^{3}$, which highlights the relative importance of silicone oil compared to water in the absorption process. As a result, the "equivalent absorption capacity" concept presents the great advantage of showing that a heterogeneous 
water/silicone oil absorbent is able to react as a pseudo-homogenous phase from a mass transfer point of view.

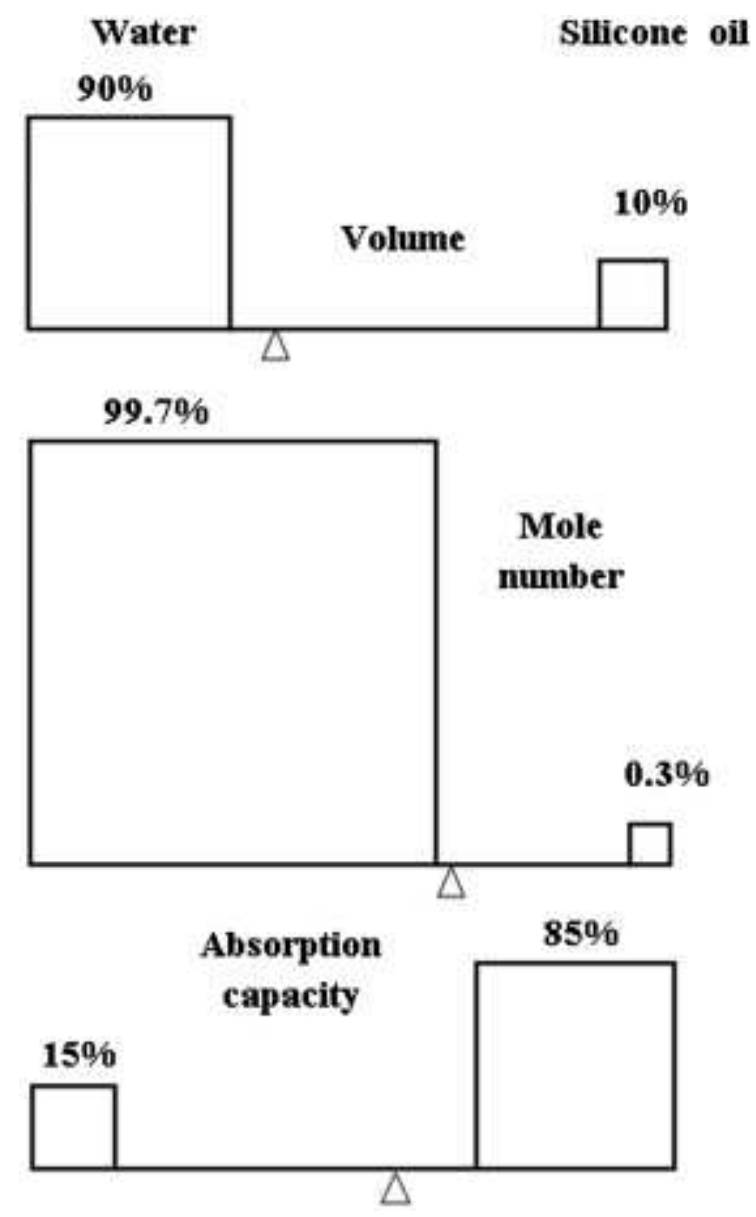

Fig. 3. DMDS absorption for a unit volume of a $(90 / 10 \mathrm{v} / \mathrm{v})$ water/silicone oil mixture $(\phi=0.1)$. Relative importance of silicone oil compared to water in terms of mole number and absorption capacity.

\section{Calculation procedure for determining the column diameter}

In designing a countercurrent gas/liquid absorber, the gas composition and flow rate are generally known. The first task is thus to determine the liquid flow from a mass balance (Fig. 4). For this purpose, an absorption factor A is usually defined (Eq. 4):

$$
A=\frac{L}{m G}
$$


The absorption factor A corresponds to the ratio of the slope of the operating line $\mathrm{L} / \mathrm{G}$ to that of the equilibrium line m (Fig. 4). A is constant when both lines are straight, which is the case for air treatment applications. Assuming that a water/silicone oil mixture has an absorption capacity equivalent to that of a pseudo-homogeneous liquid phase, the relationship between $\mathrm{m}$ and the partition coefficient is given by (Eq. 5):

$m=H_{\text {voc,mixture }}\left(\frac{1}{R T}\right)\left(\frac{M_{G} \rho_{\text {mixture }}}{M_{\text {mixture }} \rho_{G}}\right)$
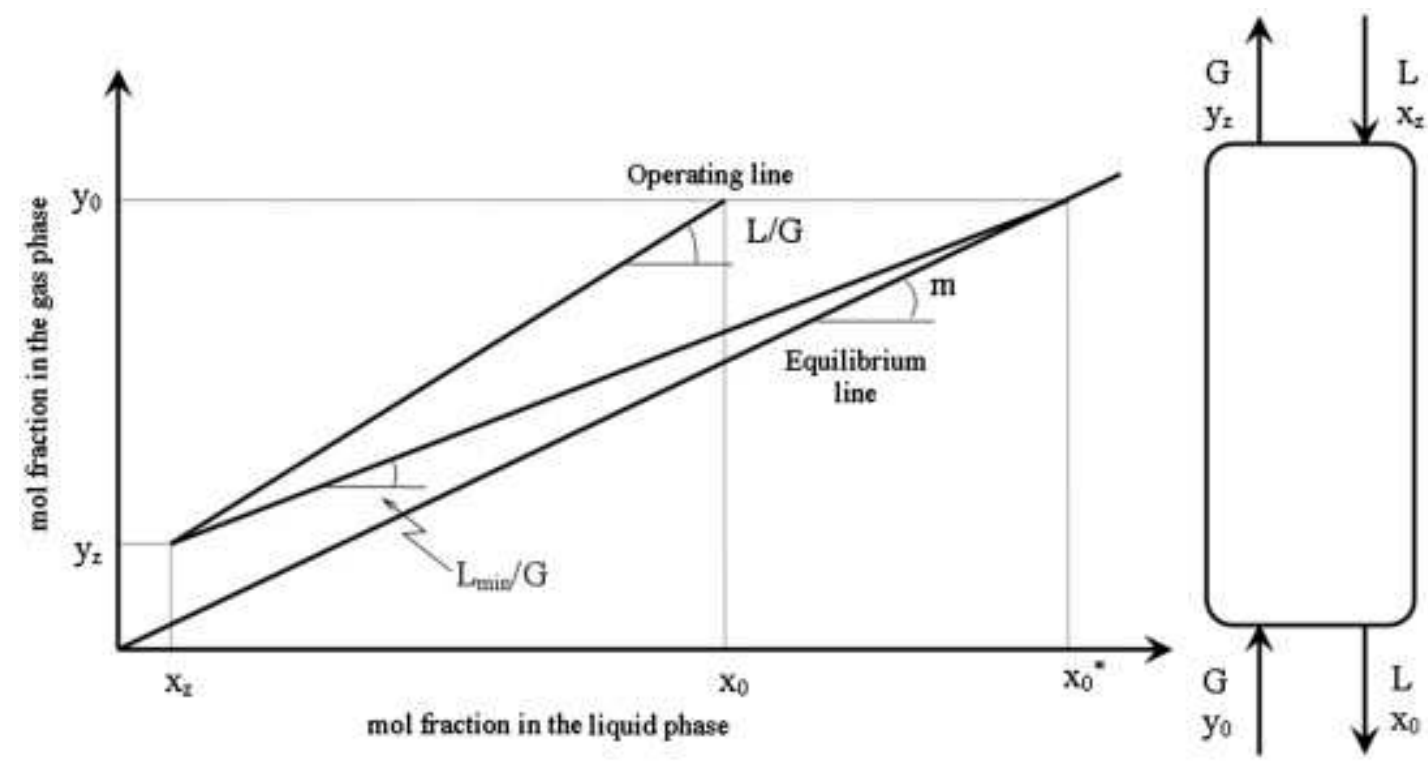

Fig. 4. Mass balance diagram for a countercurrent absorption column.

The minimum required liquid rate $\left(\mathrm{L}_{\mathrm{min}}\right)$ can be calculated from the composition of the inlet gas and the solubility of the VOC in the mixture (equilibrium being assumed). Considering the following operating conditions: (i) the gas flow rate remains constant during absorption and (ii) the water/silicone oil mixture entering the absorber is VOC free $\left(x_{z}=0\right)$, the minimum liquid-to-gas ratio $\left(\mathrm{L}_{\min } / \mathrm{G}\right)$ corresponds to the slope of the equilibrium line $(\mathrm{m})$ and consequently $\mathrm{A}=1$. It is generally specified that the liquid flow rate (L) must be as much as 25 to $100 \%$ greater than the required minimum (McCabe et al., 1993). Once obtained, the molar liquid flow rate (L) must be converted into a mass liquid flow rate $\left(\mathrm{L}^{\prime}\right)$ in order to size the column diameter by using the generalized pressure drop correlation chart (Eckert, 1970) whose abscissa and ordinate correspond to variables named $\mathrm{X}$ and $\mathrm{Y}$ (Fig. 5.): 


$$
\begin{aligned}
& X=\frac{L^{\prime}}{G^{\prime}} \sqrt{\frac{\rho_{G}}{\rho_{\text {mixture }}}} \\
& Y=\frac{G_{\Omega}^{\prime} F \mu_{\text {mixture }}^{0.2}\left(\rho_{\text {water }} / \rho_{\text {mixture }}\right)}{g \rho_{G} \rho_{\text {mixture }}}
\end{aligned}
$$

In Eqs. (6-7), $\rho_{\text {mixture }}$ corresponds to the density of the absorbing liquid (Eq. 3). In Eq. (7), $\mathrm{G}_{\Omega}$ is the mass gas flow rate per unit cross-sectional area of the column $(\Omega)$. In flooding conditions, which determine the minimum possible diameter of the column, $\mathrm{G}_{\Omega}^{\prime}=\mathrm{G}_{\Omega, \mathrm{Fl}}$ and $\mathrm{Y}=\mathrm{Y}_{\mathrm{Fl}}$. $\mathrm{F}$ is the packing factor, depending on the size of the packing material filling the column (Coulson et al., 2002) and $\mu_{\text {mixture }}$ is the dynamic viscosity of the absorbing liquid. Introduced early in the $20^{\text {th }}$ century, the generalized correlation of packed column flood points has constantly evolved following the progress in packing materials. In an extensive book devoted to the fluids dynamics of packed columns, Maćkowiack (2010) described and analyzed the most representative correlations proposed in the literature. Comparisons between correlations are critically proposed. Maćkowiack (2010) indicated that the Eckert's correlation, not applicable for vapor/liquid systems, remains valid for air/water but should be used with caution. As the objective of this study is to determine the change in the column diameter according to the silicone oil volume fraction for the same operating conditions and for the same packing material (through the change in the dimensionless ratio $D(\phi) / D(\phi=1)$ versus the silicone oil volume fraction), the accuracy of the Eckert flood correlation should be sufficient for a first approach. Once the optimum silicone oil volume fraction has been determined, the column can then be designed, in a second approach, using a more accurate method as described in the Maćkowiack's book (2010).

The conversion between the molar flow rate and the mass liquid flow rate is given by Eq. (8), which is based on the knowledge of the molecular weight of the mixture given by Eq. (2):

$$
L^{\prime}=L M_{\text {mixture }}
$$


Coupling Eqs. (1-5, 8) and Eq. (6) gives:

$$
X=\sqrt{\frac{\rho_{\text {mixture }}}{\rho_{G}}} \frac{A}{R T} \frac{1}{\left[\left(\frac{1}{H_{\text {voc, silicone oil }}}-\frac{1}{H_{\text {voc,water }}}\right) \phi+\frac{1}{H_{\text {voc,water }}}\right]}
$$

Eq. (9) can be rearranged as:

$$
X=\sqrt{\frac{\rho_{\text {mixture }}}{\rho_{G}}} \frac{A}{R T} H_{\text {voc,mixture }}
$$

According to Eq. (10), $\mathrm{X}$ changes linearly with $\mathrm{H}_{\mathrm{voc} \text {,mixture }}$ (the density of the mixture can reasonably be considered as a constant according to the silicone oil volume fraction because water and silicone oil densities are close; see Figure 5).

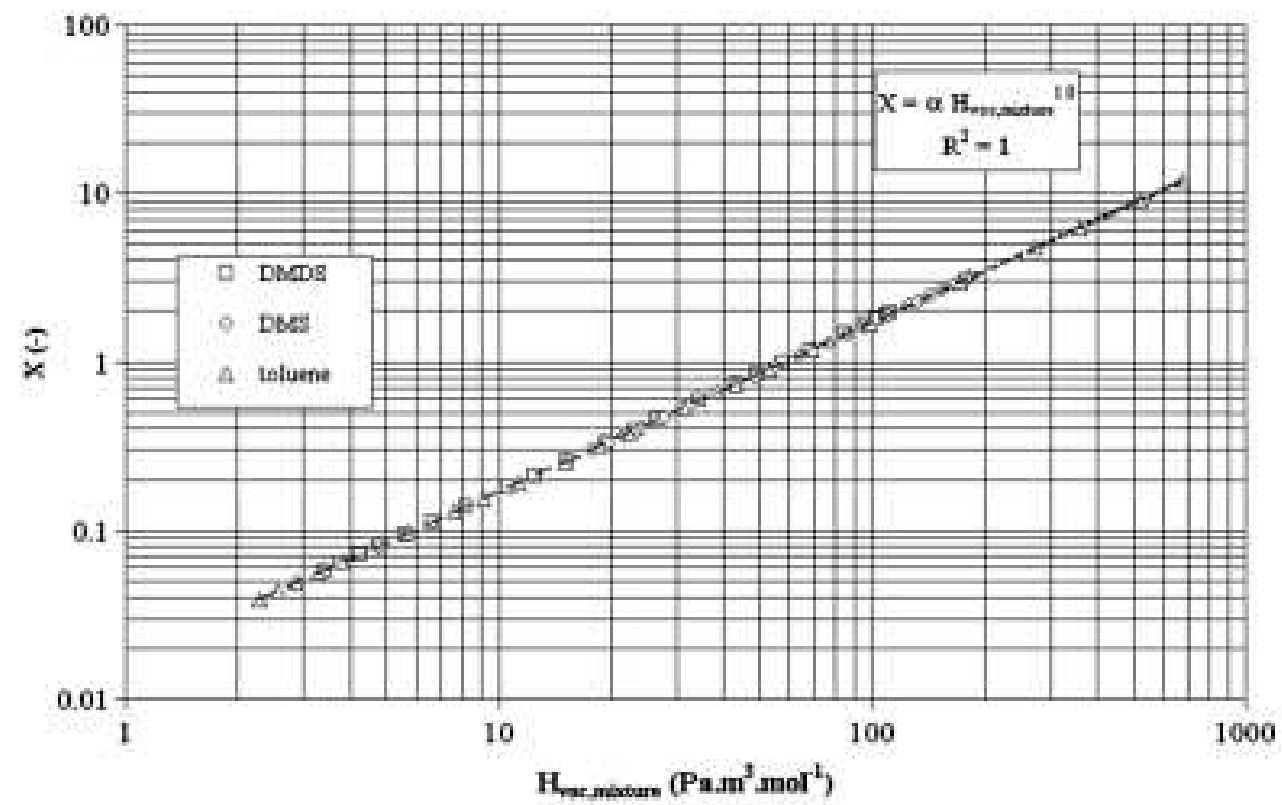

Fig. 5. Change in the dimensionless factor $X$ according to VOC partition coefficients.

From $\mathrm{X}$ values, the $\mathrm{Y}_{\mathrm{Fl}}$ factor is calculated according to Eckert's flooding curve correlation given by Piché et al. (2001) for $0.04 \leq X \leq 6$ (Eq. 11; Fig. 6). The gas flooding mass flux per unit cross-sectional area of the column $\left(\mathrm{G}_{\Omega, \mathrm{Fl}}\right)$ is then obtained from Eq. (12) derived from Eq. (7). 
$\log _{10}\left(Y_{F l}\right)=-0.289\left[\log _{10} X\right]^{2}-1.081\left[\log _{10} X\right]-1.682$

$G_{\Omega, F l}^{\prime}=\sqrt{\frac{Y_{F l} g \rho_{G} \rho_{\text {mixture }}}{F \mu_{\text {mixture }}^{0.2}\left(\rho_{\text {water }} / \rho_{\text {mixture }}\right)}}$

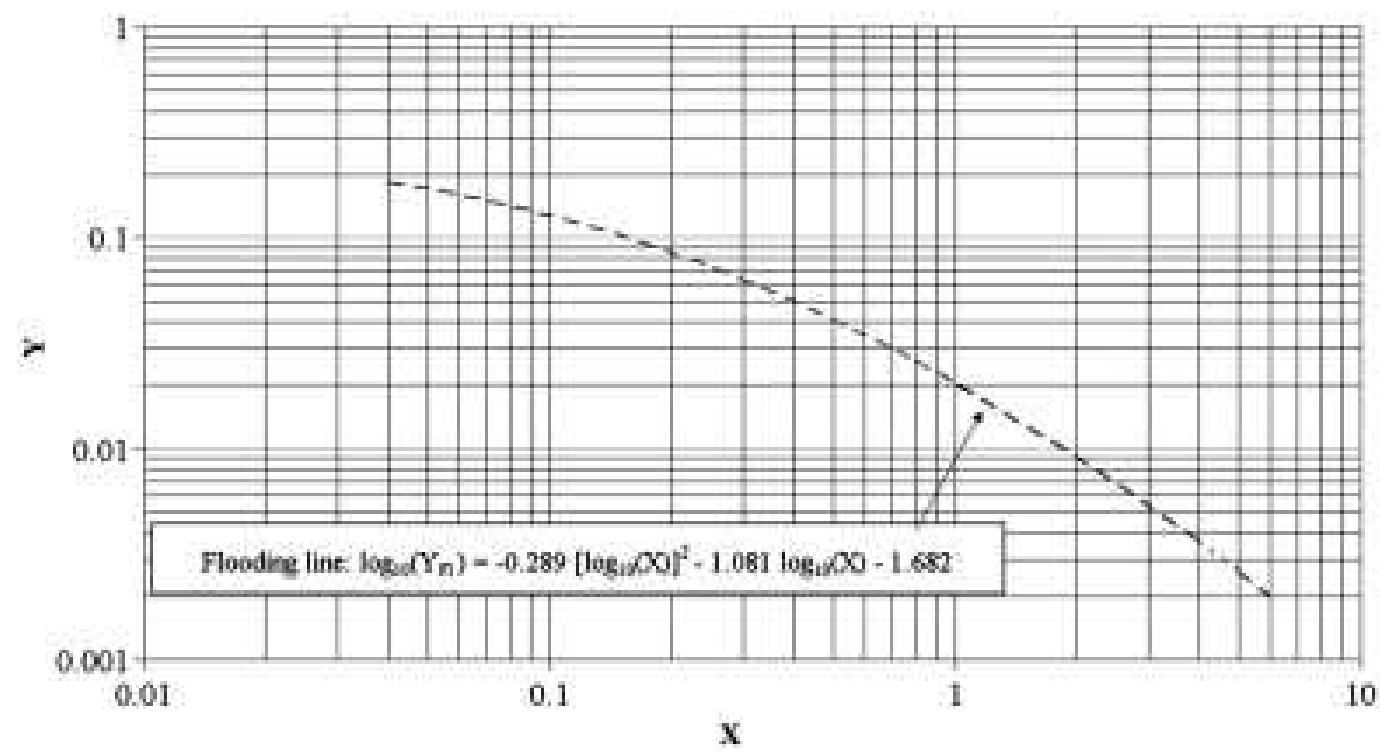

Fig. 6. Generalized pressure drop correlation (GPDC) chart from Eckert (1970); flooding line equation given by Piché et al. (2001).

Since flooding is an unacceptable operating condition, it is usually proposed to design the column diameter by using gas mass flux $\mathrm{G}_{\Omega}^{\prime}=65 \% \mathrm{G}_{\Omega, \mathrm{Fl}}$. The cross-sectional area and the column diameter are then determined using Eqs. (13-14).

$\Omega=\frac{G^{\prime}}{G_{\Omega}^{\prime}}$

$D=\sqrt{\frac{4 \Omega}{\pi}}=\sqrt{\frac{4 G^{\prime}}{0.65 \pi \sqrt{\left.\frac{Y_{F l} g \rho_{G} \rho_{\text {mixture }}}{F \mu_{\text {mixture }}^{0.2}\left(\rho_{\text {water }} / \rho_{\text {mixture }}\right.}\right)}}}$

From Eq. (14), the column diameter can be calculated for any water/silicone oil mixture $(\mathrm{D}(\phi))$ as well as for an absorption in pure silicone oil $(\mathrm{D}(\phi=1))$. The dimensionless ratio giving the change in diameter according to the silicone oil volume fraction is: 
$\frac{D(\phi)}{D(\phi=1)}=\left(\frac{Y_{F l}(\phi)}{Y_{F l}(\phi=1)}\right)^{-0.25}\left(\frac{\rho_{\text {mixture }}(\phi)}{\rho_{\text {mixture }}(\phi=1)}\right)^{-0.125}\left(\frac{\left[\rho_{\text {water }} / \rho_{\text {mixture }}(\phi=1)\right]}{\left[\rho_{\text {water }} / \rho_{\text {mixture }}(\phi)\right]}\right)^{-0.25}\left(\frac{\mu_{\text {mixture }}(\phi)}{\mu_{\text {mixture }}(\phi=1)}\right)^{0.05}$

The F parameter no longer appears in Eq. (15) because it is possible to assume that the same packing material can be used whatever the silicone oil volume fraction (there is no limitation of packing size according to column diameter). Otherwise, as $\rho_{\text {mixture }}$ is close to $\rho_{\text {water }}$ according to the silicone oil volume fraction (as indicated above), the second and third terms in the right member of Eq. (15) are close to one (they range from 0.99 to 1 and 0.98 to 1 for $0 \leq \phi \leq 1$, respectively). Moreover, considering $\mu_{\text {mixture, the silicone }}$ oil has a dynamic viscosity of the same order of magnitude as that of water (only 5 times higher) and, consequently, the term $\left(\mu_{\text {mixture }}(\phi) / \mu_{\text {mixture }}(\phi=1)\right)^{0.05}$ can logically be estimated to range from 0.92 to 1 for $0 \leq \phi \leq 1$. Eq. (15) can therefore be reasonably simplified as:

$\frac{D(\phi)}{D(\phi=1)}=\left(\frac{Y_{F l}(\phi)}{Y_{F l}(\phi=1)}\right)^{-0.25}$

\section{Results and discussion}

The calculation procedure, applicable regardless of the volumetric air flow rate, is applied for the following operating conditions: (i) atmospheric pressure $\mathrm{P}=101,325 \mathrm{~Pa}$ and temperature $\mathrm{T}=298 \mathrm{~K}\left(\rho_{\mathrm{G}}=1.186 \mathrm{~kg} / \mathrm{m}^{3}\right)$, (ii) the water/silicone oil mixture entering the absorber is VOC free $\left(\mathrm{x}_{\mathrm{z}}=0\right.$ in Fig. 4), (iii) the absorption factor is chosen: $\mathrm{A}=1.5(\mathrm{~L}=1.5 \mathrm{~m} \mathrm{G})$.

For each water/silicone oil mixture, the liquid mass flow rate needed for absorption is determined by using Eqs. $(4,8)$. From L', it is possible to calculate the volumetric mixture flow rate $\mathrm{Q}_{\mathrm{L}}$ needed for absorption $\left(\mathrm{Q}_{\mathrm{L}}\right.$ is logically related to $\mathrm{Q}_{\mathrm{G}}$ and the partition coefficients of the VOC in water and silicone oil, respectively) as well as the silicone oil amount present in the mixture $\left(\mathrm{Q}_{\text {silicone oil }(\phi)}=\phi \mathrm{Q}_{\mathrm{L}}\right)$. Furthermore, each calculated silicone oil amount can be compared with the maximum quantity of silicone 
oil needed for absorption corresponding to $\phi=1\left(\mathrm{Q}_{\text {silicone oil max }}\right)$. Data are plotted in Fig. 7. Moreover, Fig. 8 presents the change in the dimensionless factor $D(\phi) / D(\phi=1)$ versus the silicone oil volume fraction according to Eq. (16).

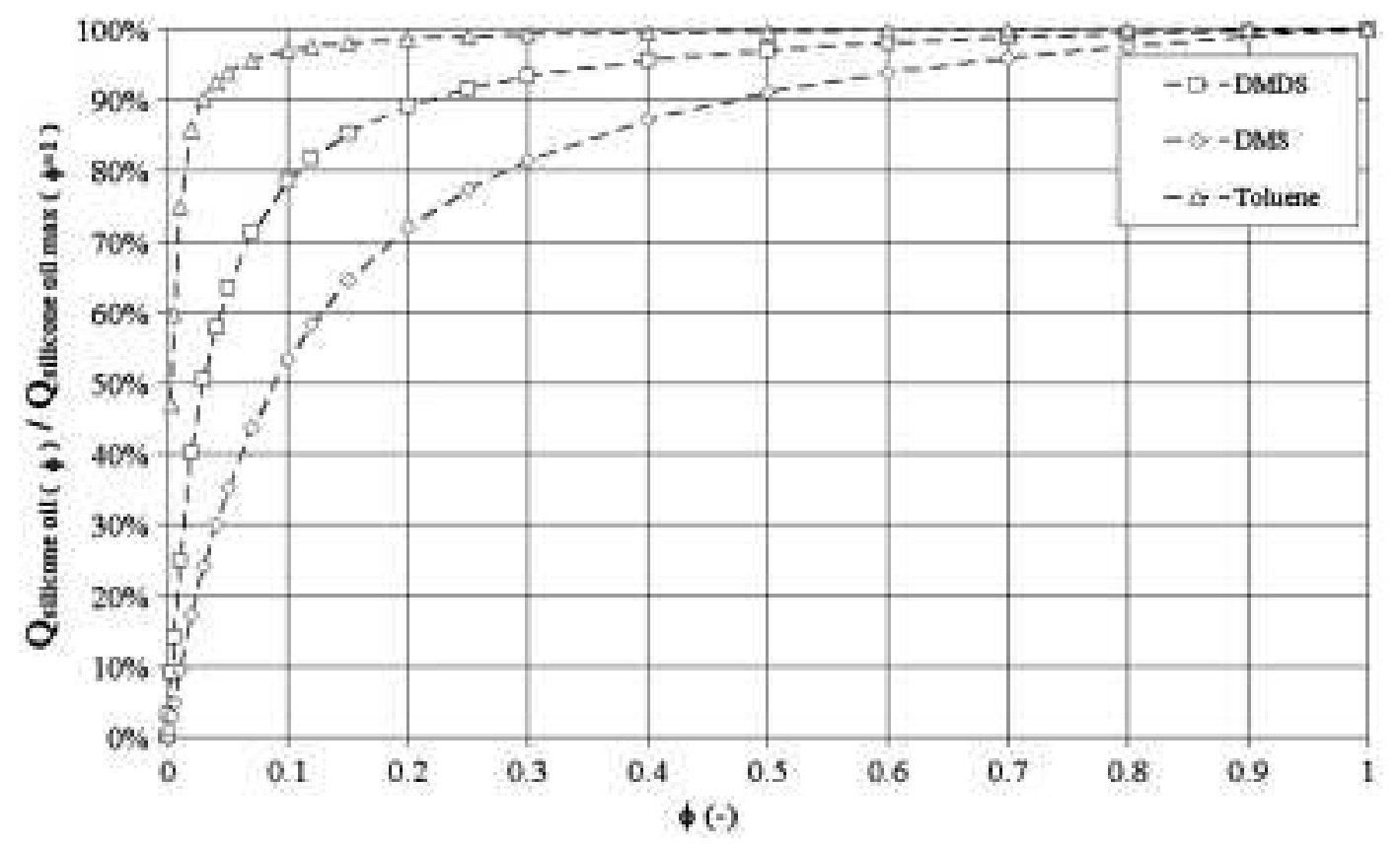

Fig. 7. Percentage of the maximum silicone oil volume needed for absorption.

For a VOC much more soluble in silicone oil than in water (large $m_{R}$ value; the case of DMDS and toluene, compared to DMS), Fig. 7 shows that it would be better to use pure silicone oil for absorption. For instance, if a water/silicone oil mixture with only $10 \%$ of solvent (i.e. $90 / 10 \mathrm{v} / \mathrm{v}$ ) is chosen to absorb toluene, it will be necessary to use a quantity of silicone oil equal to $97 \%$ of the amount needed for an absorption in the pure solvent (confirming that toluene is sparsely soluble in water). For DMDS absorption in a (90/10 $\mathrm{v} / \mathrm{v})$ mixture, it will be necessary to use a quantity of silicone oil equal to $78.5 \%$ of the maximum amount of silicone oil. Consequently, for a VOC characterized by an $\mathrm{m}_{R}$ value greater than 30 , it can be concluded that the use of a water/silicone oil mixture at low silicone oil volume fraction requires a quantity of solvent roughly equal to the amount needed for an absorption in a pure silicone oil but involves designing a column with a much larger diameter than that actually needed for an absorption in pure solvent. In other words, the absorption should be carried out by contacting the polluted air with pure silicone oil in order to minimize the column diameter. Thereby, as observed in Fig. 8, in comparison with air/water absorption $(\phi=0)$, the air/silicone oil absorption $(\phi$ 
= 1) enables a 2-fold decrease in the column diameter for DMDS and 4-fold decrease for toluene. For a $(90 / 10 \mathrm{v} / \mathrm{v})$ water/silicone oil mixture, the results are roughly the same for the two pollutants and the column diameter should be $40 \%$ greater than that calculated for an absorption in pure silicone oil.

The absorption of DMS by water/silicone oil mixtures is different because DMS is characterized by a moderate $m_{R}$ value $\left(m_{R}=10\right.$; Table 1$)$ mainly due to its weak solubility in silicone oil. As can be observed in Fig. 7, the use of a (90/10 v/v) water/silicone oil mixture requires $53.3 \%$ of the amount needed for an absorption in pure silicone oil. Accordingly, the absorption capacity of water is not insignificant compared to that of silicone oil in relation to the high value of the partition coefficient $\mathrm{H}_{\mathrm{DMS} \text {,silicone oil }}$ (Table 1). From Fig. 8 and in comparison with air/silicone oil absorption $(\phi=1)$, the column diameter should be $50 \%$ greater than that for an absorption in a $(90 / 10 \mathrm{v} / \mathrm{v})$ water/silicone oil mixture $(90 \%$ greater if an absorption in pure water $(\phi=$ 0 ) is considered). In other words, for DMS, the change in diameter versus $\phi$ is relatively moderate in relation to the $m_{R}$ value (same order of magnitude as DMDS) but the diameter of the absorber will be large related to the high value of the partition coefficient $\mathrm{H}_{\mathrm{DMS} \text {,silicone oil. }}$

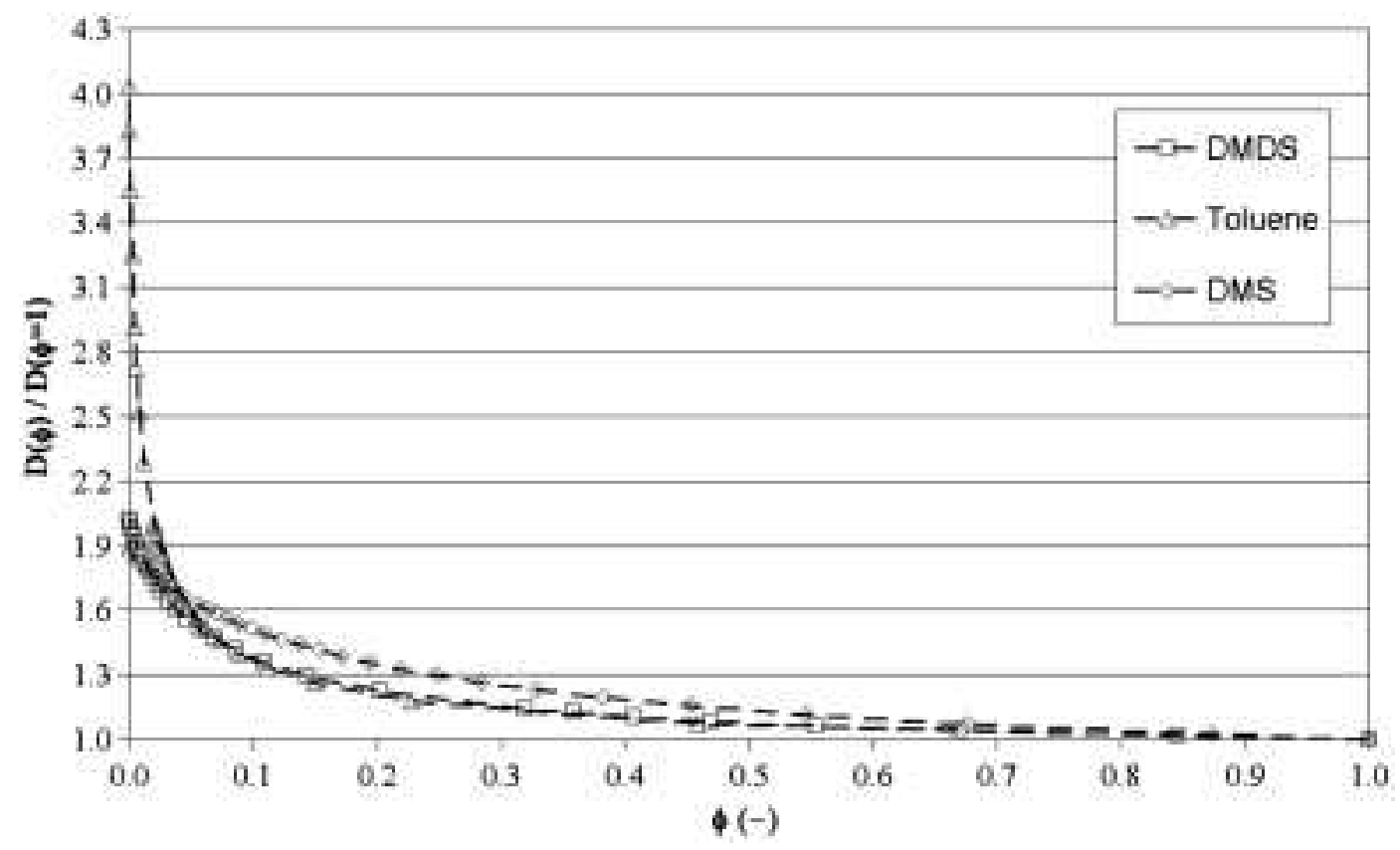

Fig. 8. Change in the dimensionless parameter $D(\phi) / D(\phi=1)$ according to the silicone oil volume fraction. 
Generally speaking, the present study has highlighted that pollutant mass transfer must be carried out between the gas phase and pure silicone oil since the VOC to be treated presents a large solubility in silicone oil. The feasibility of using a bioscrubber for the treatment of hydrophobic pollutants mainly depends on the partition coefficient

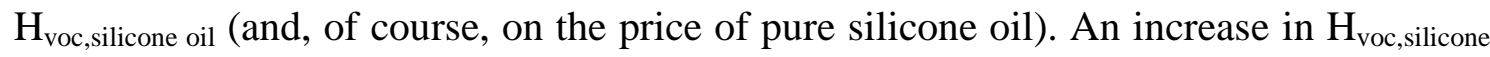
oil has only a slight influence on the column diameter $\mathrm{D}$ whereas its effect on the quantity of silicone oil $\mathrm{Q}_{\text {silicone oil }}$ is very marked (Dumont et al., 2011). Hence, for hydrophobic pollutants characterized by a large value of the partition coefficient

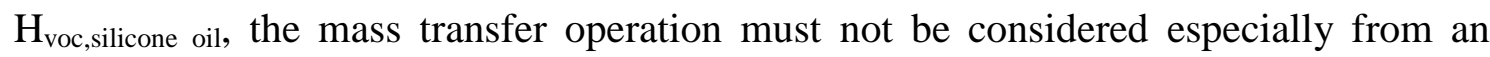
economic point of view. Conversely, for hydrophobic pollutants characterized by a

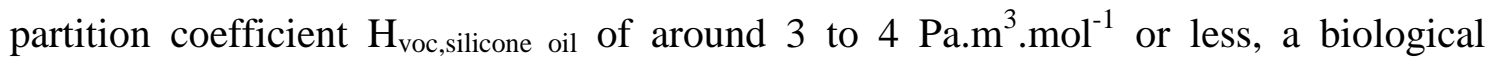
treatment in two steps could be achieved in a single unit presented in Fig. 9. The pollutant would first be transferred from air to pure silicone oil in a dumped packed column, and then degraded by the micro-organisms in a two-phase partitioning bioreactor (TPPB). In order to limit the stripping of the pollutant in the aqueous phase, the packed column should be judiciously placed above the TPPB.

When designing a dumped packed column, the column height must also be considered in order to determine the packing volume needed for absorption. The calculation of tower height requires overall mass transfer coefficients $\left(\mathrm{K}_{\mathrm{L}} \mathrm{a}\right.$ or $\left.\mathrm{K}_{\mathrm{G}} \mathrm{a}\right)$ as well as the driving forces. However, mass transfer in an air/water/silicone oil process can be described by six local mass transfer coefficients, from and to each phase. Accordingly, it is easy to understand why mass transfer mechanisms in TPPB have been only rarely studied experimentally (Quijano et al., 2009). Reviews in the literature (Dumont and Delmas, 2003; Clarke and Corriea, 2008) have highlighted the need to address the complexities of the determination of the overall mass transfer coefficient $\left(K_{L} a\right)$ in gas/liquid/liquid systems. Three markedly different $\mathrm{K}_{\mathrm{L}}$ a behavior trends have been reported according to the volume fraction ( $\phi$ generally ranges from 0 to $20 \%$ ) of the non-aqueous phase liquid used ( $\mathrm{K}_{\mathrm{L}} \mathrm{a}$ increase; $\mathrm{K}_{\mathrm{L}} \mathrm{a}$ peak; $\mathrm{K}_{\mathrm{L}} \mathrm{a}$ decrease or constant). Consequently, the prediction of $\mathrm{K}_{\mathrm{L}} \mathrm{a}$ is complex and specific experimental measurements are needed according to the NAPL used. Studying the absorption of styrene in water-silicone oil mixtures identical to those used in the present study (but only for $0 \leq \phi \leq 10 \%$ ), Dumont et al. (2006) reported that $\mathrm{K}_{\mathrm{L}}$ a remains roughly constant with increasing silicone oil volume fraction. Obviously, further studies should be 
carried out in order to determine the $\mathrm{K}_{\mathrm{L}} \mathrm{a}$ change for larger silicone oil volume fractions $(0 \leq \phi \leq 100 \%)$. To date (and to the best of our knowledge), the literature data are still too disparate to allow the TPPB technology to move from lab-scale to full-scale applications. To conclude, it is interesting to note that, since the absorption of the pollutant should be carried out directly between air and pure silicone oil (as suggested above), $\mathrm{K}_{\mathrm{L}}$ a could easily be estimated and compared to the air/water system using literature correlations. As a result, absorber design would be easier.

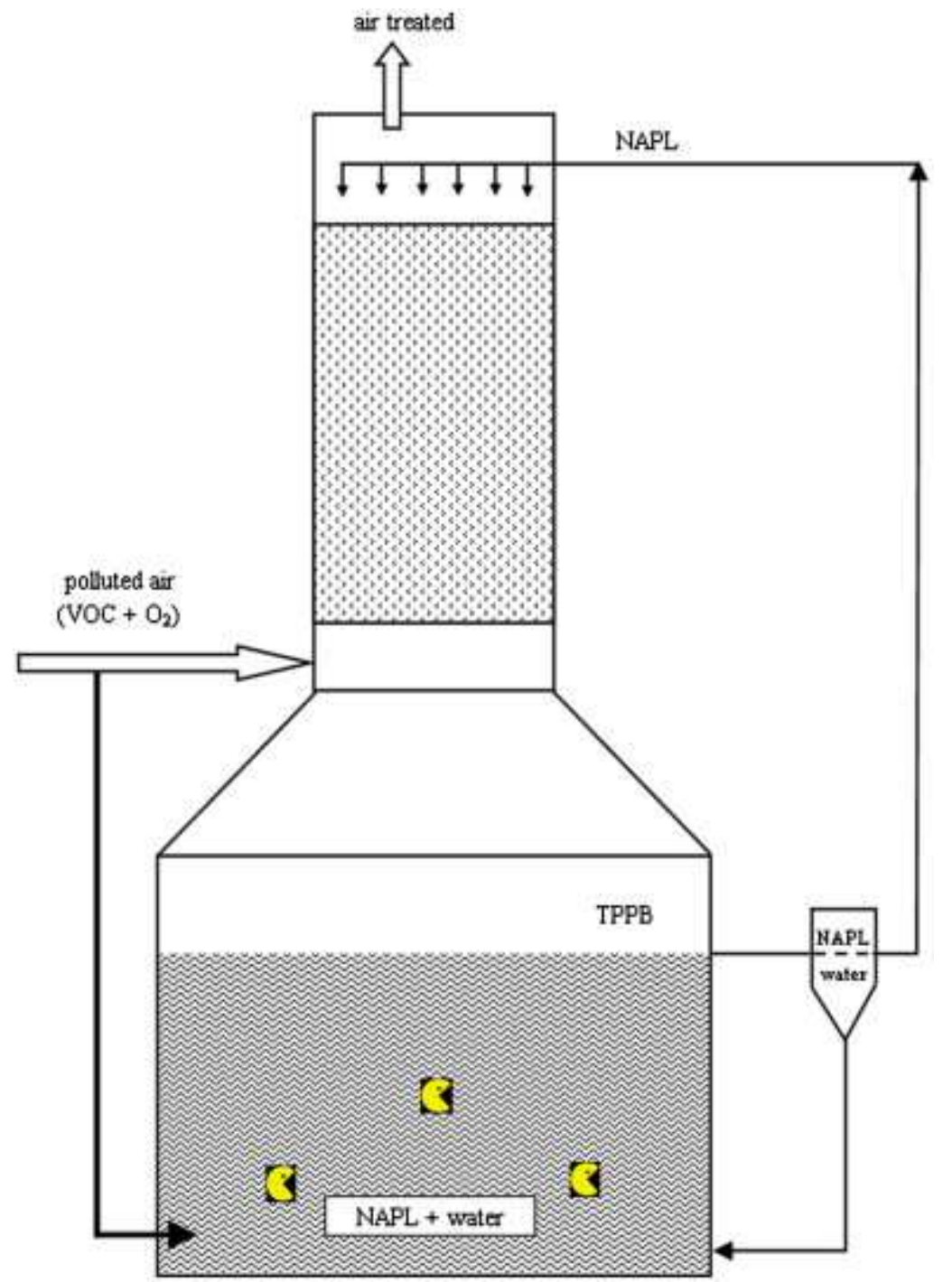

Fig. 9. Single unit for VOC treatment (NAPL=silicone oil). 


\section{Conclusion}

A calculation procedure based on the "equivalent absorption capacity" concept has been applied to determine the diameter change of a gas-liquid contactor column as a function of the volumetric fraction of the organic solvent in a water/silicone oil mixture. For

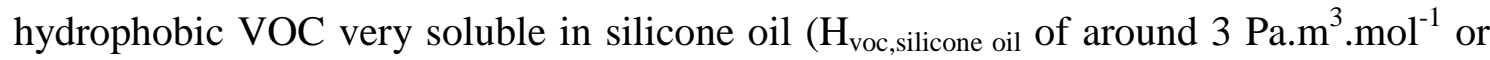
less), whatever their affinity for water (case of toluene and DMDS), it seems unwise to use water/silicone oil mixtures for mass transfer. The contact between the polluted air and pure silicone oil requires roughly the same amount of silicone oil as for a (90/10 v/v) water/silicone oil mixture, but enables a 2-fold decrease in the column diameter. For hydrophobic VOC moderately soluble in silicone oil (case of DMDS), the treatment by a bioscrubber using water/silicone oil mixtures should be carefully considered because large amounts of silicone oil are required.

\section{Nomenclature}
A: absorption factor (-)
D: column diameter $(\mathrm{m})$
$\mathrm{F}$ : packing factor $\left(\mathrm{m}^{-1}\right)$
$\mathrm{G}$ : molar flow of the gas $\left(\mathrm{mol} \cdot \mathrm{h}^{-1}\right)$
$\mathrm{G}^{\prime}$ : mass flow of the gas $\left(\mathrm{kg} \cdot \mathrm{h}^{-1}\right)$
$\mathrm{G}_{\Omega}$ : gas flow rate $\left(\mathrm{kg} \cdot \mathrm{m}^{-2} \cdot \mathrm{h}^{-1}\right)$
$\mathrm{H}:$ partition coefficient $\left(\mathrm{Pa} \cdot \mathrm{m}^{3} \cdot \mathrm{mol}^{-1}\right)$
$\mathrm{K}_{\mathrm{L}} \mathrm{a}$ : overall mass transfer coefficient $\left(\mathrm{s}^{-1}\right)$
$\mathrm{L}$ : molar flow of the liquid (mol.h ${ }^{-1}$ )
$\mathrm{L}$ ': mass flow of the liquid $\left(\mathrm{kg} \cdot \mathrm{h}^{-1}\right)$
$\mathrm{L}_{\Omega}$ : liquid flow rate $\left(\mathrm{kg} \cdot \mathrm{m}^{-2} \cdot \mathrm{h}^{-1}\right)$
M: molecular weight (kg. mol $\left.{ }^{-1}\right)$
$\mathrm{m}$ : slope of the equilibrium line (-)
$\mathrm{m}_{\mathrm{R}}$ : distribution coefficient (-)
$\mathrm{R}$ : ideal gas constant $\left(8.314 \mathrm{~J} . \mathrm{mol}^{-1} \cdot \mathrm{K}^{-1}\right)$
$\mathrm{T}$ : temperature $(\mathrm{K})$
$\mathrm{Q}_{\mathrm{G}}$ : gas flow rate $\left(\mathrm{m}^{3} \cdot \mathrm{h}^{-1}\right)$ 
$\mathrm{Q}_{\mathrm{L}}$ : liquid mixture flow rate $\left(\mathrm{m}^{3} \cdot \mathrm{h}^{-1}\right)$

$\mathrm{Q}_{\text {silicone oil }}$ : silicone oil flow rate $\left(\mathrm{m}^{3} \cdot \mathrm{h}^{-1}\right) ; \mathrm{Q}_{\text {silicone oil }}=\phi \mathrm{Q}_{\mathrm{L}}$

$\mathrm{x}$ : molar fraction of VOC in the liquid phase (-)

$\mathrm{y}$ : molar fraction of VOC in the gas phase (-)

\section{Greek letters}

$\phi$ : silicone oil volume fraction (-)

$\eta$ : dynamic viscosity (Pa.s)

$\mu$ : dynamic viscosity (cPo)

$\rho:$ density $\left(\mathrm{kg} \cdot \mathrm{m}^{-3}\right)$

$\Omega$ : cross-sectional area $\left(\mathrm{m}^{2}\right)$

\section{Superscripts}

*: equilibrium

\section{Subscripts}

0: bottom of the column

DMS: relative to dimethyl sulfide

DMDS: relative to dimethyl disulfide

$\mathrm{Fl}$ : flooding

G: gas phase

L: liquid phase

max: maximum

min: minimum

mixture: relative to water/silicone oil mixture

silicone oil: relative to silicone oil

VOC: Volatile Organic Compound

water: relative to water

z: top of the column

$\Omega$ : relative to the cross-sectional area of the column 


\section{References}

Billet, R., Schultes, M., 1999. Prediction of mass transfer columns with dumped and arranged packings. Updated summary of the calculation method of Billet and Schultes. Trans IChemE, Part A 77, 498-504.

Clarke, K.G., Correia, L.D.C., 2008. Oxygen transfer in hydrocarbon-aqueous dispersions and its applicability to alkane bioprocesses: a review. BioChem. Eng. J. 39, 405-429.

Coulson, J.M., Richardson, J.F., Backhurst, J.R., Harker, J.H., 2002. Coulson and Richardson's Chemical Engineering. Volume 2, Particle technology and separation processes. $5^{\text {th }}$ ed. Butterworth-Heinemann, Oxford.

Darracq, G., Couvert, A., Couriol, C., Amrane, A., Thomas, D., Dumont, E., Andrès, Y., Le Cloirec, P., 2010. Silicone oil: an effective absorbent for the removal of hydrophobic volatile organic compounds. J. Chem. Technol. Biotechnol. 85, 309-313. Daugulis, A.J., 2001. Two-phase partitioning bioreactors: a new technology platform for destroying xenobiotics. Trends in Biotechnology 19, 457-462.

Dumont, E., Delmas, H., 2003. Mass transfer enhancement of gas absorption in oil-inwater systems: a review. Chem. Eng. Proc. 42, 419-438.

Dumont, E., Andrès, Y., Le Cloirec, P., 2006a. Effect of organic solvents on oxygen mass transfer in multiphase systems: Application to bioreactors in environmental protection. Biochem. Eng. J. 30, 245-252.

Dumont, E., Andrès, Y., Le Cloirec, P., 2006b. Mass transfer coefficients of styrene and oxygen into silicone oil emulsions in a bubble reactor. Chem. Eng. Sci. 61, 5612-5619. Dumont, E., Darracq, G., Couvert, A., Couriol, C., Amrane, A., Thomas, D., Andrès, Y., Le Cloirec, P., 2010. Determination of partition coefficients of three volatile organic compounds (dimethylsulphide, dimethyldisulphide, toluene) in water/silicone oil mixtures, Chem. Eng. J. 162, 927-934.

Dumont, E., Darracq, G., Couvert, A., Couriol, C., Amrane, A., Thomas, D., Andrès, Y., Le Cloirec, P., 2011. VOC absorption in a countercurrent packed-bed column using water/silicone oil mixtures: influence of silicone oil volume fraction, Chem. Eng. J. 168, 241-248. 
Eckert, J.S., 1970. Selecting the proper distillation column packing. Chem. Eng. Prog. $66,39-44$.

Green, D.W., Perry, R.H., 2008. Perry's Chemical Engineers Handbook. $8^{\text {th }}$ ed. McGraw-Hill, New-York.

Kister, H.Z., Scherffius, J., Afshar, K., Abkar, E., 2007. Realistically predict capacity and pressure drop for packed columns. Chem. Eng. Prog. 103, 28-38.

Kundu, A., Dumont, E., Duquenne A-M., Delmas, H., 2003. Mass transfer characteristics in gas-liquid-liquid systems. Can. J. Chem. Eng. 81, 640-646.

McCabe, L.W., Smith, J.C., Harriot, P., 1993. Unit Operations of Chemical Engineering. $5^{\text {th }}$ ed., McGraw-Hill Chemical Engineering Series.

Piché, S., Larachi, F., Grandjean, B.P.A., 2001. Flooding capacity in Packed towers: database, correlations, and analysis. Ind. Eng. Chem. Res. 40, 476-487.

Quijano, G., Hernandez, M., Thalasso, F., Munoz, R., Villaverde, S., 2009. Two-phase partitioning bioreactors in environmental biotechnology. App. Microbiol. Biotechnol. 84, 829-846. 